SUPPLEMENTARY INFORMATION

\title{
One-Pot Synthesis of Adipic Acid from Guaiacol in Escherichia coli
}

Jack T. Suitor, Simon Varzandeh and Stephen Wallace*

Institute for Quantitative Biology, Biochemistry and Biotechnology, School of Biological

Sciences, University of Edinburgh, Roger Land Building, Alexander Crum Brown Road, King's

Buildings, Edinburgh, EH9 $3 F F$

*Correspondence to: stephen.wallace@ed.ac.uk 


\section{Supplementary Materials}

\section{General Materials and Methods}

E. coli BL21(DE3) and E. coli DH5a cells were obtained from Dr Louise Horsfall and Dr Janice Bramham (University of Edinburgh), respectively. The strains were stored as 1:1 v/v LB:glycerol stocks at $-80{ }^{\circ} \mathrm{C}$ and used as required. E. coli Lemo21(DE3) competent cells were purchased from New England Biolabs.

Proton nuclear magnetic resonance spectra ( ${ }^{1} \mathrm{H}$ NMR) were recorded using a Bruker AVA400, AVA500, Pro500 or AVA600 NMR spectrometer at the specified frequency at $298 \mathrm{~K}$. Proton chemical shifts are expressed in parts per million ( $\mathrm{ppm}, \delta$ scale) and are referenced to residual protium in the NMR solvent (DMSO-d6 $=2.50 \mathrm{ppm} ; \mathrm{CDCl}_{3}=7.26 \mathrm{ppm}$ ). Carbon nuclear magnetic resonance spectra $\left({ }^{13} \mathrm{C}\right.$ NMR) were recorded using a Bruker AVA400, AVA500, Pro500 or AVA600 NMR spectrometer at the specified frequency at $298 \mathrm{~K}$. Chemical shifts are quoted in parts per million (ppm, $\delta$ scale) and are referenced to the carbon resonances of the NMR solvent $\left(\mathrm{CDCl}_{3}=77.2 \mathrm{ppm}\right)$. Coupling constants, $J$, are measured to the nearest $0.1 \mathrm{~Hz}$ and are presented as observed. Data is represented as: chemical shift, integration, multiplicity $(\mathrm{s}=$ singlet, $\mathrm{d}=$ doublet, $\mathrm{t}=$ triplet, $\mathrm{q}=$ quartet, $\mathrm{dd}=$ doublet of doublet, $\mathrm{m}=$ multiplet and/or multiple resonances), coupling constant $(J)$ in Hertz.

HPLC analysis was carried out using a Thermo Scientific Dionex UltiMate 3000 Series UHPLC instrument and a HyperSil Gold C18 column (150x3 mm x $3 \mu \mathrm{m})$. Analytes were detected at 206, 190, 260 , and $270 \mathrm{~nm}$.

Unless otherwise noted, starting materials and reagents were obtained from commercial suppliers and were used without further purification. All water used experimentally was purified with a Suez Select purification system (18M $\Omega . \mathrm{cm}, 0.2 \mu \mathrm{M}$ filter). All NMR and HPLC solvents were purchased from commercial suppliers. For all quantitative measurements by ${ }^{1} \mathrm{H}$ NMR spectroscopy, 1,3,5trimethoxybenzene (TMB, $2.7 \mathrm{mM}$ ) was used as an internal standard. For all quantitative measurements by HPLC, caffeine $(51 \mu \mathrm{M})$ was used as an internal standard.

All synthetic genes were codon-optimised for E. coli BL21(DE3) and then synthesised using GeneArt ${ }^{\mathrm{TM}}$ (Thermo Scientific). Oligonucleotide primers were synthesised by Integrated DNA Technologies. Recombinant plasmid DNA was purified with a Miniprep Kit (Qiagen). Chaperone plasmids were purchased from Takara Biosciences. Plasmid pET22b was obtained from Prof. Chris French (University of Edinburgh). Plasmid pETDuet-1 was purchased from Novagen. Plasmid pQLinkN was obtained from Dr Konrad Buessow (Helmholtz Centre for Infection Research in Braunschweig, Germany). All restriction enzymes were purchased from Thermo Fisher as FastDigest ${ }^{\mathrm{TM}}$ enzymes. Unless otherwise specified, all restriction enzyme digests were carried out at $37^{\circ} \mathrm{C}$ using FastDigest ${ }^{\mathrm{TM}}$ Green buffer. All plasmids were sequenced by Sanger sequencing at Edinburgh Genomics (Edinburgh, UK). Taq 
Polymerase (New England Biolabs) was used for all colony PCR reactions. Phusion High-Fidelity DNA Polymerase (New England Biolabs) was used for all other PCR reactions. T4 DNA ligase (Thermo Scientific) was used for all ligation reactions. For pQLink cloning, T4 polymerase (New England Biolabs) was used in buffer 2.1 following the manufacturer's protocol. All standard Taq PCR reactions were performed using the following conditions: initial denaturation $\left(95^{\circ} \mathrm{C}, 30 \mathrm{~s}\right), 35$ thermocycles $(30 \mathrm{~s}$ denaturation at $95{ }^{\circ} \mathrm{C}$, annealing at $50-65{ }^{\circ} \mathrm{C}$ for $20 \mathrm{~s}$, and extension at $68{ }^{\circ} \mathrm{C}$ for $60 \mathrm{~s} / \mathrm{kb}$ ), and final extension $\left(68^{\circ} \mathrm{C}\right.$ for $\left.10 \mathrm{~min}\right)$. All standard Phusion PCR reactions were performed using the following conditions: initial denaturation $\left(98^{\circ} \mathrm{C}, 30 \mathrm{~s}\right), 35$ thermocycles $\left(10 \mathrm{~s}\right.$ denaturation at $98^{\circ} \mathrm{C}$, annealing at $50-72{ }^{\circ} \mathrm{C}$ for $20 \mathrm{~s}$, and extension at $72{ }^{\circ} \mathrm{C}$ for $\left.30 \mathrm{~s} / \mathrm{kb}\right)$, and final extension $\left(72{ }^{\circ} \mathrm{C}\right.$ for $\left.10 \mathrm{~min}\right)$.

For agarose gel electrophoresis, agarose $(1 \% \mathrm{w} / \mathrm{v})$ TAE gels containing a $1 \mathrm{kB}$ Generuler ladder (Thermo Scientific) were run at $80 \mathrm{~V}$ for $45 \mathrm{~min}$ and visualised using SYBR Safe ${ }^{\mathrm{TM}}$. For SDS-PAGE, 12-well 12\% acrylamide Bis-Tris NuPAGE gels (Thermo Scientific) containing an unstained Precision plus standard ladder (Biorad) were used to analyse samples. Gels were run in 1x MES buffer (Novagen) at $50 \mathrm{~V}$ for $30 \mathrm{~min}$ followed by $150 \mathrm{~V}$ for $2 \mathrm{~h}$.

Optical densities of $E$. coli cultures were determined using a DeNovix DS-11 UV/Vis spectrophotometer by measuring absorbance at $600 \mathrm{~nm}$. Unless stated otherwise, E. coli cells were cultured at $37^{\circ} \mathrm{C}$ with shaking at $220 \mathrm{rpm}$.

\section{Media, Strains and Culturing Conditions}

Luria Bertani Lennox (LB) Media was prepared according to the following recipe: bacto-tryptone (10 $\mathrm{g} / \mathrm{L})$, yeast extract $(5 \mathrm{~g} / \mathrm{L})$ and $\mathrm{NaCl}(10 \mathrm{~g} / \mathrm{L})$ in $\mathrm{MQ} \mathrm{H}_{2} \mathrm{O}$. LB was autoclaved at $121{ }^{\circ} \mathrm{C}$ for $20 \mathrm{~min}$, cooled and stored at room temperature. LB agar was made using the same recipe but with the addition of agar (15 g/L). Terrific Broth (TB) Media was prepared according to the following recipe: yeast extract (24 g/L), tryptone (20 g/L), glycerol (4 mL/L), Potassium Phosphate Buffer $\left(72 \mathrm{mM} \mathrm{K}_{2} \mathrm{HPO}_{4}\right.$; $12.5 \mathrm{~g} / \mathrm{L}$ ), in $1 \mathrm{~L} \mathrm{MQ} \mathrm{H}_{2} \mathrm{O}$. TB was autoclaved using the same protocol as LB. M9-glucose media was prepared according to the following procedure: A $5 \mathrm{x}$ stock solution was prepared dissolving $\mathrm{Na}_{2} \mathrm{HPO}_{4}$ $(85.5 \mathrm{~g}), \mathrm{KH}_{2} \mathrm{PO}_{4}(15 \mathrm{~g})$ and $\mathrm{NaCl}(2.5 \mathrm{~g})$ in $1 \mathrm{~L}$ of $\mathrm{MQ} \mathrm{H}_{2} \mathrm{O}$. The $\mathrm{pH}$ was adjusted to 7.4 using $\mathrm{NaOH}$ $(5 \mathrm{M})$ and autoclaved at $121{ }^{\circ} \mathrm{C}$ for $20 \mathrm{~min}$. Filter sterilised $\mathrm{MgSO}_{4}(2 \mathrm{~mL} ; 1 \mathrm{M}), \mathrm{CaCl}_{2}(2 \mathrm{~mL} ; 50 \mathrm{mM})$, $\left(\mathrm{NH}_{4}\right)_{2} \mathrm{SO}_{4}(3.8 \mathrm{~mL} ; 2 \mathrm{M})$ and glucose $(20 \mathrm{~mL} ; 20 \% \mathrm{w} / \mathrm{v})$ were added to a $5 \mathrm{x}$ buffer solution $(200 \mathrm{~mL})$ and the total volume adjusted to $1 \mathrm{~L}$ using autoclaved $\mathrm{MQ} \mathrm{H}_{2} \mathrm{O}$. All other reagents used in culturing were filter sterilised using a $0.22 \mu \mathrm{m}$ filter (Millex).

All chemically competent cells were prepared via treatment with calcium chloride. ${ }^{1}$ For use in protein expression and cloning, chemically competent E. coli BL21(DE3), E. coli Lemo21(DE3), E. coli BL21(DE3)_pGro7, E. coli BL21(DE3)_pKJE7, E. coli BL21(DE3)_pTf16 and E. coli DH5a cells were prepared and transformed with an appropriate plasmid via heat-shock at $42{ }^{\circ} \mathrm{C}$ for $45 \mathrm{~s}$. Cells were 
recovered in $1 \mathrm{~mL}$ of SOC media for $1 \mathrm{~h}$ at $37^{\circ} \mathrm{C}$. Transformants were selected by plating on LB agar containing appropriate antibiotics and incubating at $37{ }^{\circ} \mathrm{C}$ overnight. A single colony was picked and grown overnight at $37{ }^{\circ} \mathrm{C}$ and $220 \mathrm{rpm}$ in $10 \mathrm{~mL}$ of LB containing the appropriate antibiotics. The resulting overnight culture $(0.5 \mathrm{~mL})$ was added to $0.5 \mathrm{~mL}$ of $1: 1 \mathrm{v} / \mathrm{v}$ water:glycerol solution, frozen in liquid nitrogen, stored at $-80{ }^{\circ} \mathrm{C}$ and used as required. For all microbiological experiments, antibiotics were used at the following concentrations: $100 \mathrm{mg} / \mathrm{mL}$ ampicillin, $34 \mathrm{mg} / \mathrm{mL}$ chloramphenicol.

\section{Adipic Acid Production Reactions}

A $-80{ }^{\circ} \mathrm{C}$ LB:glycerol stock of E. coli BL21(DE3), E. coli Lemo21(DE3), or E. coli BL21(DE3)AiscR, harbouring the pAA or pAA', and pGro7, pKJE7 or pTf16 plasmids was inoculated into $10 \mathrm{~mL}$ of LB and grown at $37{ }^{\circ} \mathrm{C}(220 \mathrm{rpm})$ for $18 \mathrm{~h}$. The saturated overnight culture $(5 \mathrm{~mL})$ was then inoculated into Terrific Broth (250 mL in a $500 \mathrm{~mL}$ baffled Erlenmeyer flask) containing appropriate antibiotic(s) and grown aerobically at $37{ }^{\circ} \mathrm{C}(220 \mathrm{rpm})$ until the cultures reached $\mathrm{OD}_{600}=0.6-0.8$ (ca. 2.5-3 h). At this point, DMSO (2.5 $\mathrm{mL}$ of a $5 \mathrm{M}$ solution) was added. Cultures were then incubated at room temperature $\left(21^{\circ} \mathrm{C}, 200 \mathrm{rpm}\right)$ for $30 \mathrm{~min}$ before being induced using IPTG $(100 \mu \mathrm{L}$ of a $1 \mathrm{M}$ solution). As required, arabinose $(12 \mathrm{mM})$, benzyl alcohol $(10 \mathrm{mM})$, or rhamnose $(10-100 \mu \mathrm{M})$ were added. Following $18 \mathrm{~h}$ of incubation at room temperature $\left(21^{\circ} \mathrm{C}, 200 \mathrm{rpm}\right)$, cultures were pelleted via centrifugation $(2700 \mathrm{xg}$, $19{ }^{\circ} \mathrm{C}$ for $\left.10 \mathrm{~min}\right)$. The cell pellet was resuspended in $50 \mathrm{~mL}$ of wash buffer ( $50 \mathrm{mM}$ sodium phosphate, $\mathrm{pH}$ 7.2) and centrifuged at $\left(2700 \mathrm{xg}, 19^{\circ} \mathrm{C}\right)$ for $10 \mathrm{~min}$. The cell pellet was resuspended in $50 \mathrm{~mL}$ of wash buffer and $25 \mu \mathrm{L}$ of this was used to determine $\mathrm{OD}_{600}$ before being centrifuged $\left(2600 \mathrm{xg} 19{ }^{\circ} \mathrm{C}\right.$, $10 \mathrm{~min})$ and resuspended in an appropriate volume of reaction buffer $(50 \mathrm{mM}$ sodium phosphate, $\mathrm{pH}$ $7.2,3 \% \mathrm{w} / \mathrm{v}$ glucose, $0.3 \% \mathrm{w} / \mathrm{v} \mathrm{NaCl}, 5 \mathrm{mM}$ catechol) or M9-reaction buffer (M9 media containing 3\% $\mathrm{w} / \mathrm{v}$ glucose and $5 \mathrm{mM}$ catechol) to give a final $\mathrm{OD}_{600}=122$. Resuspending the pellet in an appropriate volume of reaction buffer resulted in dilution of $5 \mathrm{mM}$ catechol substrate due to the volume of the pellet. The resulting total volume of cell suspension was noted and used to calculate actual catechol concentration. This was used in subsequent yield calculations. For reactions at low cell density $\left(\mathrm{OD}_{600}\right.$ $=12$ ), parent $\mathrm{OD}_{600}=122$ cell suspensions in reaction buffer were diluted ten-fold with additional reaction buffer. For each reaction, $3 \mathrm{~mL}$ of cell suspension in reaction buffer were aliquoted into a 15 $\mathrm{mL}$ falcon tube, sealed and incubated at $37{ }^{\circ} \mathrm{C}(220 \mathrm{rpm})$ for the desired time period. Reactions were sampled following a $0-2 \mathrm{~h}$ incubation for the time-course analyses and after $24 \mathrm{~h}$ of incubation for all other experiments. 


\section{Cloning}

\section{pAA plasmid construction}

The catA (UniProt ID O33948) and ER (UniProt ID G2TQU6) were synthesised with desired restriction enzyme sites appended to the 5' and 3' ends of each coding sequence. The resulting pMAT-ER plasmid was digested with NcoI and NotI. Following gel purification, the $E R$ coding sequence was then inserted into the MCS-1 of a linearized pETDuet-1 vector using NdeI and XhoI to afford ER-pETDuet-1. This was then repeated to clone the catA coding sequence into the MCS-2 of ER-pETDuet-1 using NdeI and XhoI to afford ER-catA-pETDuet-2 (pAA), which was confirmed by Sanger sequencing. Sequencing primers used were "CatA Seq Primer 1", "CatA Seq Primer 2", "Enoate Reductase Seq Primer I", "Enoate Reductase Seq Primer 2" and "Enoate Reductase Seq Primer 3" (Table S2).

\section{$\triangle i s c R$ BL21(DE3) strain generation}

E. coli BL21(DE3) $4 i s c R$ was generated via modification of the reported protocol by Court et. $a l^{2}$ except using the following modifications: (i) the linear CamR cassette was purified via gel extraction and the coding DNA sequence was amplified a second time via PCR, (ii) cells were washed with glycerol (10\% v/v aqueous solution) when preparing electrocompetent cells and were electroporated at $2.5 \mathrm{kV}(200 \Omega, 25 \mu \mathrm{Fd})$, (iii) cells were grown for $5 \mathrm{~h}$ following electroporation. The pSIM27 plasmid was used for recombineering and was obtained from the Court Lab (National Institute of Health, MD, USA). The chloramphenicol resistance cassette was constructed using "CamR Forward" and "CamR Reverse" primers (Table S2) using an annealing temperature of $65{ }^{\circ} \mathrm{C}$ under standard PCR conditions (see S1.1). Knockout colonies were confirmed via colony PCR using primers "iscR KOA", "iscR KO $B$ ", "iscR KO C", and "iscR KO D" (Table S2) using an annealing temperature of $50{ }^{\circ} \mathrm{C}$ under standard PCR conditions (see S1.1). Genomic DNA of E. coli BL21(DE3)AiscR was purified using a GenElute ${ }^{\mathrm{TM}}$ Bacterial Genomic DNA Purification kit (Sigma Aldrich) following the manufacturer's protocol. Figure $\mathrm{S} 1$ demonstrates construction of the $\Delta i s c R$ knockout strain. Primers A and B anneal upstream and downstream of the iscR gene, respectively. Together they yield an approximately $600 \mathrm{bp}$ PCR amplicon in unmodified E. coli BL21(DE3) cells. Upon insertion of the CamR cassette at the iscR locus, an approximately $1000 \mathrm{bp}$ amplicon is produced. Primers $\mathrm{C}$ and $\mathrm{D}$ anneal to the CamR cassette, producing PCR products only when the CamR cassette has been inserted into the genome. 
A

E. coli BL21(DE3)

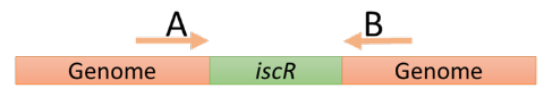

E. coli BL21(DE3)_DiscR

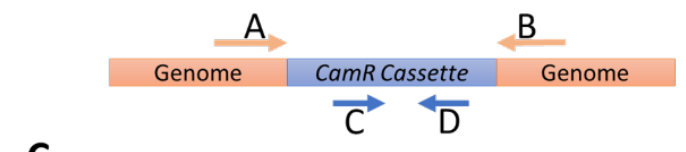

C
Primers C + D

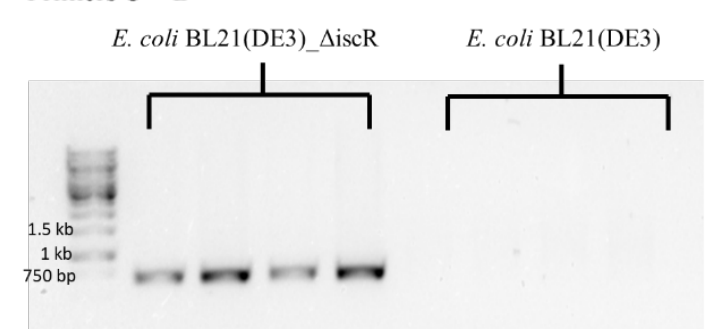

B Primers $\mathrm{A}+\mathrm{B}$

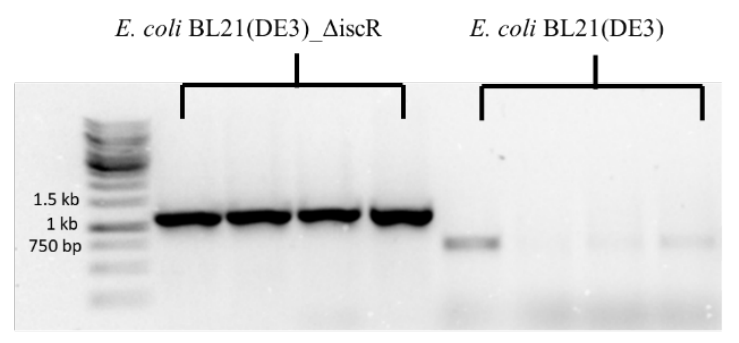

Primers A + D

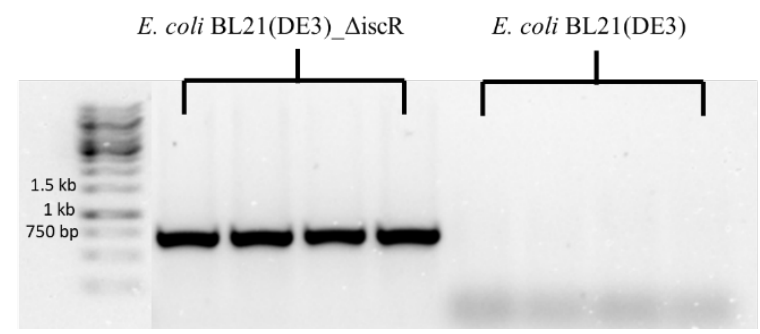

Figure S1. Confirming the $\triangle$ iscR knock-out by colony PCR. A) Schematic showing primer design. B-D) Analysis of colony PCR reactions by agarose gel electrophoresis.

\section{pAA' plasmid construction}

Coding sequence templates for pAA' construction are as follows: gcoA from Amycolatopsis sp. (UniProt ID P0DPQ7), gcoB from Amycolatopsis sp. (UniProt ID P0DPQ8), gcoA from Rhodococcus rhodochrous (GenBank ID MK007067.1), and gcoB from Rhodococcus rhodochrous (GenBank ID MK007068.1). Following PCR extension of the coding sequences (Table S1), the synthesized genes were sub-cloned into the $\mathrm{pQLinkN}$ vector using BamHI and NotI. The pAA' plasmid was assembled using the pQLink ligation independent cloning (LIC) method previously described by Büssow et. al. ${ }^{3}$ After Sanger sequencing, the pAA' plasmid was transformed into chemically competent E. coli BL21(DE3) cells.

Table S1:

\begin{tabular}{|l|l|l|l|}
\hline Gene/Template & Forward Primer & Reverse Primer & Annealing Temp. \\
\hline catA (P. putida) & catA F pQLinkN & catA R pQLinkN & $64{ }^{\circ} \mathrm{C}$ \\
\hline bcER (B. coagulans) & ER F pQLinkN & ER R pQLinkN & $59{ }^{\circ} \mathrm{C}$ \\
\hline gcoA(Amycolatopsis sp.) & Aa-gcoA F pQLinkN & Aa-gcoA R pQLinkN & $65{ }^{\circ} \mathrm{C}$ \\
\hline gcoB (Amycolatopsis sp.) & Aa-gcoB F pQLinkN & Aa-gcoB R pQLinkN & $66{ }^{\circ} \mathrm{C}$ \\
\hline gcoA (R. rhodochrous) & $R r$-gcoA F pQLinkN & $R r$-gcoA R pQLinkN & $65{ }^{\circ} \mathrm{C}$ \\
\hline gcoB $($ R. rhodochrous) & $R r$-gcoB F pQLinkN & $R r$-gcoB R pQLinkN & $68{ }^{\circ} \mathrm{C}$ \\
\hline Colony PCR & pQTEV3U & pQTEV3L & $59{ }^{\circ} \mathrm{C}$ \\
\hline
\end{tabular}




\section{Oligonucleotide primers}

Table S2:

\begin{tabular}{|c|c|}
\hline Primer & Sequence \\
\hline catA F petDuet1 & CAGAGCTCACATATGACCGTGAAAATTAGCC \\
\hline catA R petDuet1 & CTGACGATCTCGAGTCATCATGAATTCCCTTCTTGCAGTGCACG \\
\hline catA F pQLinkN & CAGAGCTCAGGATCCATGACCGTGAAAATTAGCCATACC \\
\hline catA R pQLinkN & $\begin{array}{l}\text { CTGACGATGCGGCCGCTCATCATGAATTCCCTTCTTGCAGTGCA } \\
\text { C }\end{array}$ \\
\hline ER F pQLinkN & CAGAGCTCAGGATCCATGGGAAAATACAAGAAACTGT \\
\hline ER R pQLinkN & $\begin{array}{l}\text { CTGACGATGCGGCCGCTCATCACGCGGCTGCTAAATTGGCTGCC } \\
\text { ACTTC }\end{array}$ \\
\hline Aa-gcoA F pQLinkN & CAGAGCTCAGGATCCATGACCACCACCGAACGTC \\
\hline Aa-gcoA R pQLinkN & CTGACGATGCGGCCGCTCATCAAACTTCCCAGGTCACATGCAG \\
\hline Aa-gcoB F pQLinkN & CAGAGCTCAGGATCCATGACCTTTGCAGTTAGCGTTGG \\
\hline Aa-gcoB R pQLinkN & $\begin{array}{l}\text { CTGACGATGCGGCCGCTCATCAGCTTGCCGGTGTGAATTTTTCA } \\
\text { C }\end{array}$ \\
\hline$R r$-gcoA F pQLinkN & CAGAGCTCAGGATCCATGACCAGCACACTGAGCTG \\
\hline$R r$-gcoA R pQLinkN & CTGACGATGCGGCCGCTCATCAAATTTCCCAACGTGCATGCA \\
\hline$R r$-gcoB F pQLinkN & $\begin{array}{l}\text { CAGAGCTCAGGATCCATGGGTGATCTGACCATGAGCTATACCCT } \\
\text { GA }\end{array}$ \\
\hline$R r$-gcoB R pQLinkN & $\begin{array}{l}\text { CTGACGATGCGGCCGCTCATCAACCTGCCGGTGTAAAACGTTCA } \\
\text { CGACGAATACGAC }\end{array}$ \\
\hline T7-lac promoter $\mathrm{F}$ & CGACTCACTATAGGGGAATTGTG \\
\hline T7-lac terminator $\mathrm{R}$ & CTAGTTATTGCTCAGCGGTGG \\
\hline catA seq primer 1 & GTACACCGCGTACCATTGAAGG \\
\hline catA seq primer 2 & CCAGCAGGTCCAGACATTCTTG \\
\hline ER seq primer 1 & CGTTATGCAATGGCACCGATG \\
\hline ER seq primer 2 & GCATTGTGCGCAAATTGGTG \\
\hline ER seq primer 3 & GAATATTCAAGCCTGGGTTGTGC \\
\hline pQTEV3U & TATAAAAATA GGCGTATCAC GAGG \\
\hline pQTEV3L & CCAGTGATTT TTTTCTCCAT TTT \\
\hline CamR F & $\begin{array}{l}\text { AAATACCCGACTAAATCAGTCAAGTAAATAGTTGACCAATTTAC } \\
\text { TCGGGATGTGACGGAAGATCACTTCG }\end{array}$ \\
\hline CamR R & $\begin{array}{l}\text { TTAAGCGCGTAACTTAACGTCGATCGCGTCTTGTGTGCGGGTGC } \\
\text { GTGGCGACCAGCAATAGACATAAGCG }\end{array}$ \\
\hline iscR KO A & ACGCCACGATAAAAAAATGGC \\
\hline iscR KO B & GTGTTTACGGAGTATTTAGCAC \\
\hline iscR KO C & GTATGGCAATGAAAGACGGT \\
\hline iscR KO D & AAAACTGGTGAAACTCACCC \\
\hline
\end{tabular}




\section{Microscopy}

For each imaging experiment, reaction aliquots $(1 \mu \mathrm{L})$ were added to $\mathrm{MQ} \mathrm{H}_{2} \mathrm{O}(5 \mu \mathrm{L})$ on a microscope slide coated with agarose $\left(1 \% \mathrm{w} / \mathrm{v}\right.$ in $\left.\mathrm{H}_{2} \mathrm{O}\right)$. Images were acquired directly at a resolution of $0.1 \mu \mathrm{M}$ per pixel using a Zeiss Axiovert 200 fluorescence microscope equipped with a Photometrics Evolve ${ }^{\mathrm{TM}} 512$ EMCCD camera.

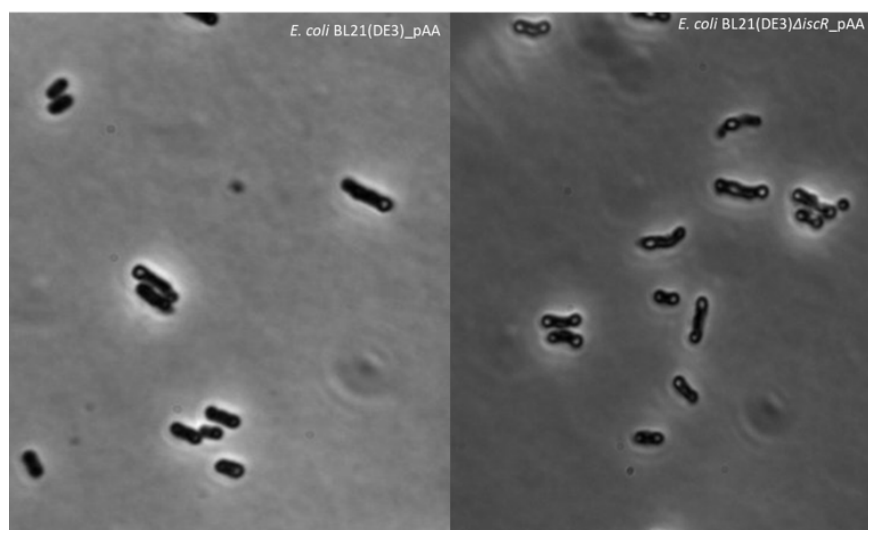

Figure S2. Microscopy images of E. coli BL21(DE3)_pAA and E. coli BL21(DE3)AiscR_pAA cells

\section{Quantification Methods}

\section{${ }^{1}$ H NMR}

For NMR analysis, reaction aliquots $(900 \mu \mathrm{L})$ were pelleted via centrifugation (1666 xg, $2 \mathrm{~min})$. The supernatant was transferred to a $1.5 \mathrm{~mL}$ Eppendorf tube, frozen at $-80{ }^{\circ} \mathrm{C}$ and lyophilised $\left(-50{ }^{\circ} \mathrm{C}, 16\right.$ h, 0.002 mbar). Dried samples were re-dissolved in $d_{6}$-DMSO $(750 \mu \mathrm{L})$ containing TMB $(2.7 \mathrm{mM})$ and filtered through a cotton wool plug into an NMR tube. Adipic acid was quantified using characteristic proton resonances at $2.20 \mathrm{ppm}$ and $1.48 \mathrm{ppm}$. TMB peaks are at $6.08 \mathrm{ppm}$ and $3.70 \mathrm{ppm}$. 

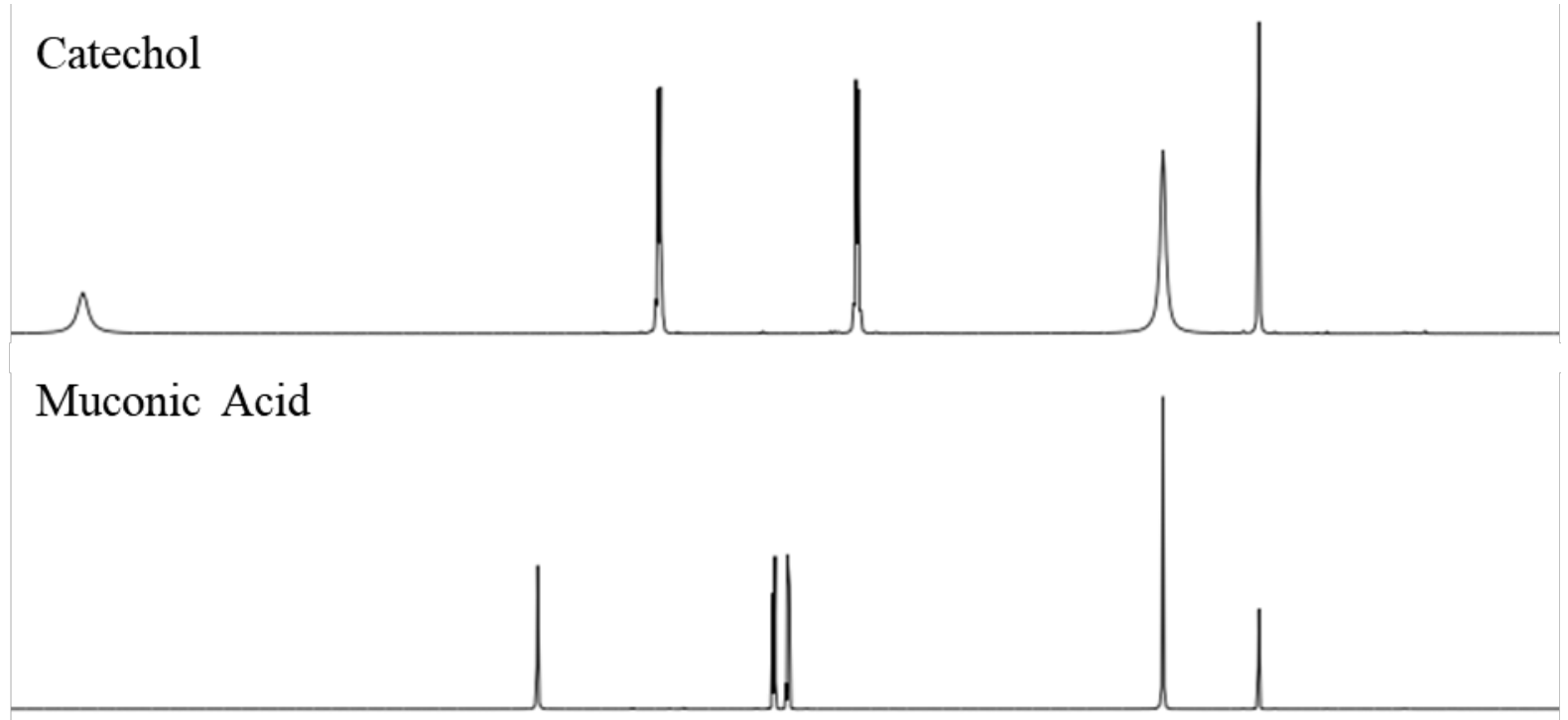

\section{Adipic Acid}

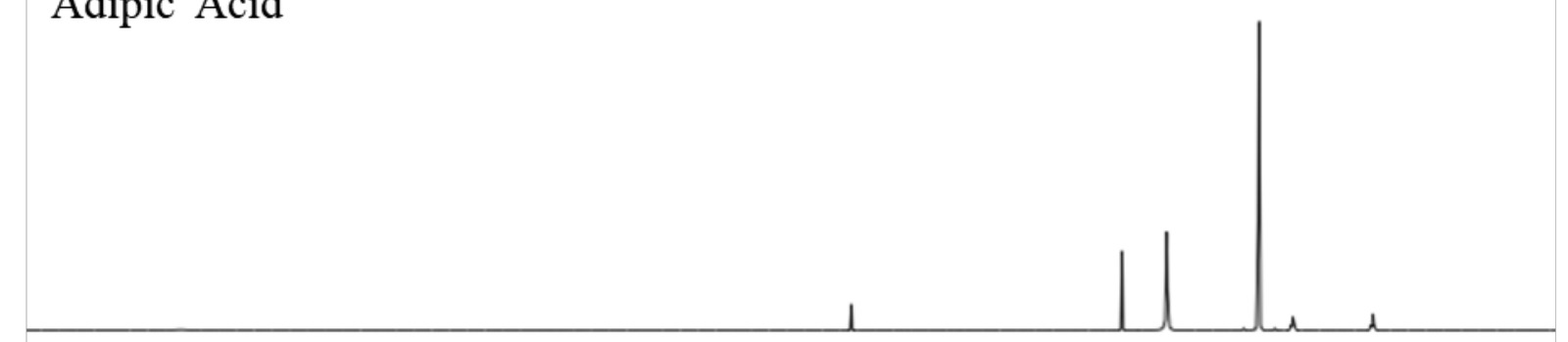

\section{E. coli $\mathrm{BL} 21(\mathrm{DE} 3)$ pAA}

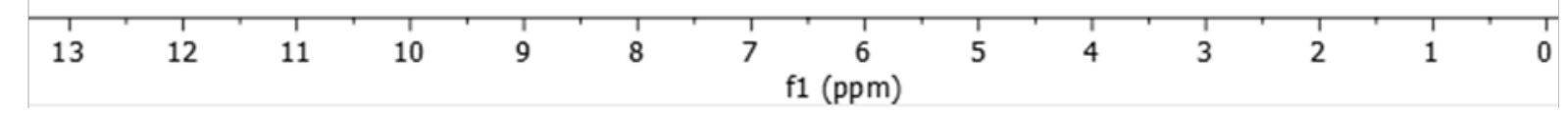

Figure S3. ${ }^{1} \mathrm{H}$ NMR spectra of reaction intermediates and lyophilized culture extracts.

\section{Reverse-phase HPLC}

Analytes were separated using a gradient from 5 to $10.5 \% \mathrm{MeCN}\left(0.1 \% \mathrm{v} / \mathrm{v}\right.$ TFA) in $\mathrm{H}_{2} \mathrm{O}(0.1 \% \mathrm{v} / \mathrm{v}$ TFA). Peak areas were collected at $206 \mathrm{~nm}$ and integrated relative to an internal standard of caffeine. Elution times were as follows: 2-hexenedioic acid (7.6 min), adipic acid ( $8.8 \mathrm{~min})$, catechol (10.6 min), muconic acid (12.2 min), caffeine (13.3 min) and guaiacol (17.9 min). A standard curve was constructed 
over a defined range of analyte concentrations to ensure accurate detection via this method providing linear relationships of $\mathrm{pA}_{\text {adipic acid }} / \mathrm{pA}_{\text {caffeine }}=0.076 \mathrm{c}_{\text {adipic acid }}-0.0031, \mathrm{pA}_{\text {muconic acid }} / \mathrm{pA}_{\text {caffeine }}=2.20 \mathrm{c}_{\text {muconic }}$ acid +0.12 and $\mathrm{pA}_{\text {catechol }} / \mathrm{pA}_{\text {caffeine }}=4.42 \mathrm{c}_{\text {catechol }}+1.12$ (Figure $\mathrm{S} 4, \mathrm{pA}=$ peak area). Samples were diluted accordingly prior to injection. Calibration curves are provided below.

For HPLC analysis, reaction aliquots $(100 \mu \mathrm{L})$ were diluted into $\mathrm{MQ} \mathrm{H}_{2} \mathrm{O}(100 \mu \mathrm{L})$ before adding $\mathrm{MeCN}(400 \mu \mathrm{L}+0.15 \% \mathrm{v} / \mathrm{v}$ TFA). Samples were vortexed for $10 \mathrm{~s}$ and left to stand at room temperature for $30 \mathrm{~min}$. Samples were vortexed again for $10 \mathrm{~s}$ before being centrifuged (1666 $\mathrm{xg}, 10 \mathrm{~min})$. The supernatant was transferred into $1.5 \mathrm{~mL}$ Eppendorf tubes and left to concentrate by evaporation in a fume hood for 48-72 h. Sample residues were then re-dissolved in water ( $300 \mu \mathrm{L})$ containing caffeine $(0.01 \mathrm{mg} / \mathrm{mL})$ and TFA $(0.1 \% \mathrm{v} / \mathrm{v})$. Samples were filtered through a spin column filter (Agilent) via centrifugation $(1666 \mathrm{xg}, 10 \mathrm{~min})$. The filtrate $(10 \mu \mathrm{L})$ was then analysed by HPLC. The average recovery of adipic acid from biological samples was determined to be $88 \pm 3 \%$. Where appropriate, relative concentrations of guaiacol within batch samples are reported due to its volatility during sample preparation.
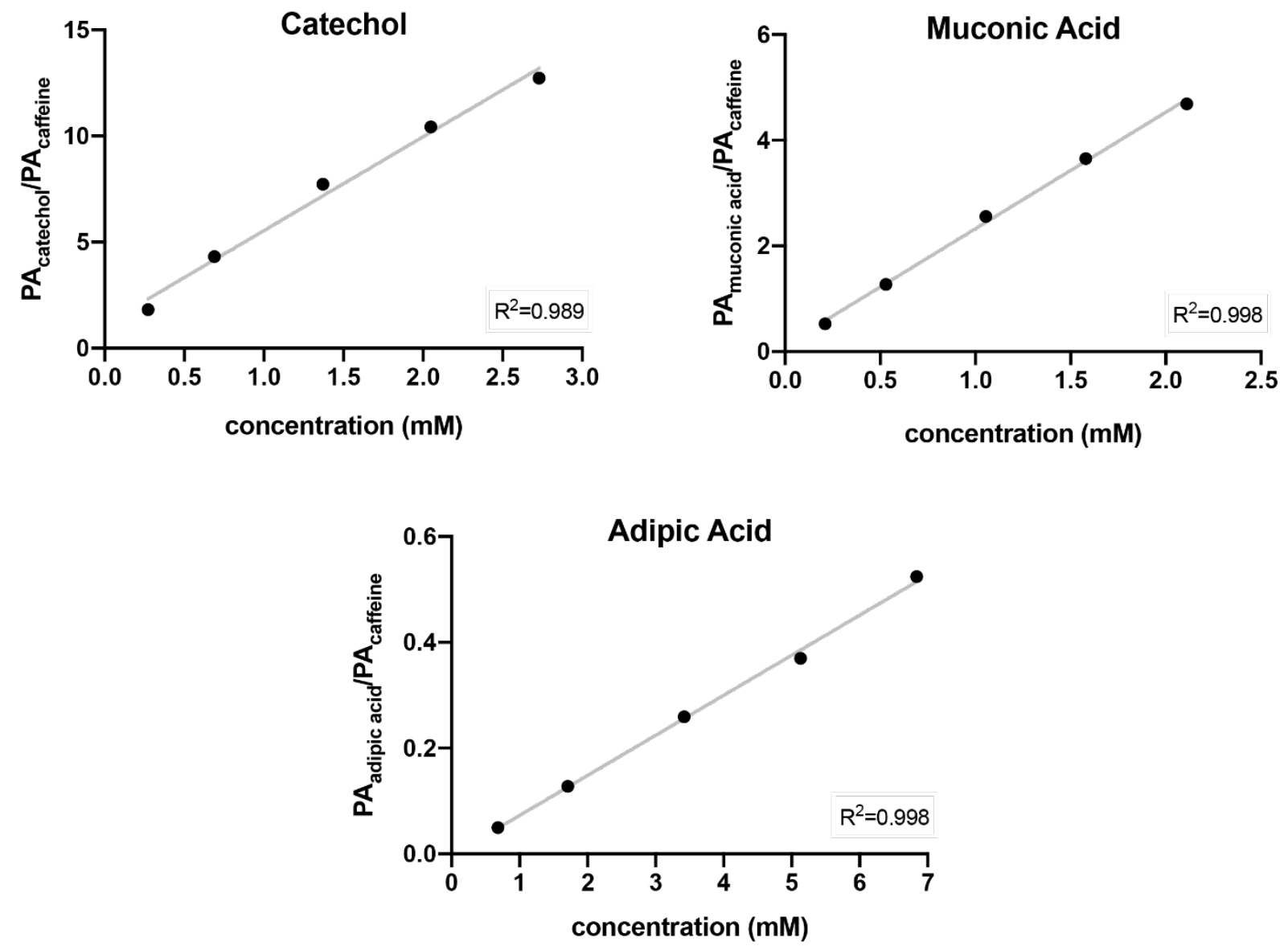

Figure S4. HPLC calibration curves 
Table S3: Adipic acid production from catechol in Na-Pi ${ }^{[a]}$

\begin{tabular}{|c|c|c|c|c|c|c|c|}
\hline entry & E. coli BL21(DE3) & $\begin{array}{c}\text { Time } \\
\text { (h) }\end{array}$ & $\begin{array}{l}\text { OD }_{600} \\
\text { (a.u.) }\end{array}$ & $\begin{array}{c}\text { Catechol } \\
(\mathbf{m M})\end{array}$ & $\begin{array}{c}\text { Muconic } \\
\text { Acid } \\
(\mathbf{m M})\end{array}$ & $\begin{array}{c}\text { Adipic } \\
\text { Acid } \\
(\mathbf{m M}) \\
\end{array}$ & $\begin{array}{c}\text { Yield } \\
(\%)\end{array}$ \\
\hline 1 & pET22b & 24 & 122 & $5 \pm 0.04$ & 0 & 0 & 0 \\
\hline 2 & $\mathrm{pAA}$ & 24 & 122 & 0 & 0 & $3.7 \pm 0.2$ & $85 \pm 4.8$ \\
\hline 3 & pAA (dead) & 24 & 122 & 0 & $2.6 \pm 0.22$ & 0 & 0 \\
\hline 4 & pAA + pTf16 & 24 & 122 & 0 & 0 & $4.0 \pm 0.3$ & $88 \pm 6.9$ \\
\hline 5 & pAA + pGro 7 & 24 & 122 & 0 & 0 & $3.7 \pm 1=0.2$ & $84 \pm 4.0$ \\
\hline 6 & pAA + pKJE7 & 24 & 122 & 0 & 0 & $3.0 \pm 0.1$ & $70 \pm 2.4$ \\
\hline 7 & pAA_ $\triangle i s c R$ & 24 & 122 & 0 & 0 & $4.1 \pm 0.1$ & $89 \pm 1.2$ \\
\hline 8 & Lemo $^{[\mathrm{b}]}$ & 24 & 122 & 0 & 0 & $3.6 \pm 0.03$ & $86 \pm 2.0$ \\
\hline 9 & Lemo $^{[\mathrm{c}]}$ & 24 & 122 & 0 & 0 & $2.3 \pm 0.3$ & $56 \pm 4.6$ \\
\hline 10 & Lemo $^{[\mathrm{d}]}$ & 24 & 122 & 0 & $0.45 \pm 0.1$ & $1.4 \pm 0.8$ & $32 \pm 0.7$ \\
\hline 11 & $\mathrm{pAA}^{[\mathrm{e}]}$ & 24 & 122 & 0 & 0 & $4.2 \pm 0.2$ & $98 \pm 4.6$ \\
\hline 12 & $\mathrm{pAA}^{[\mathrm{f}]}$ & 24 & 122 & 0 & $0.9 \pm 1.6$ & $1.7 \pm 1.2$ & $38 \pm 28$ \\
\hline 13 & pAA & 24 & 12 & 0 & $2.9 \pm 0.1$ & 0 & 0 \\
\hline 14 & $\mathrm{pAA}+\mathrm{pTf16}$ & 24 & 12 & 0 & $2.4 \pm 0.2$ & 0 & 0 \\
\hline 15 & pAA + pGro 7 & 24 & 12 & 0 & $3.4 \pm 0.1$ & 0 & 0 \\
\hline 16 & pAA + pKJE7 & 24 & 12 & 0 & $3.0 \pm 0.2$ & $0.6 \pm 0.2$ & $13 \pm 3.0$ \\
\hline 17 & pAA_AiscR & 24 & 12 & 0 & $4.5 \pm 0.1$ & 0 & 0 \\
\hline 18 & pAA & 6 & 122 & 0 & 0 & $4.0 \pm 0.1$ & $91 \pm 2$ \\
\hline 19 & pAA + pGro7 & 6 & 122 & 0 & 0 & $3.9 \pm 0.01$ & $89 \pm 0.01$ \\
\hline 20 & pAA + pTf16 & 6 & 122 & 0 & 0 & $3.8 \pm 0.04$ & $87 \pm 0.9$ \\
\hline
\end{tabular}

[a] reactions were incubated for $24 \mathrm{~h}$. [b] $10 \mu \mathrm{M}$ L-rhamnose was added. [c] $40 \mu \mathrm{M}$ L-rhamnose was added. [d] $100 \mu \mathrm{M}$ L-rhamnose was added. [e] $10 \mathrm{mM}$ benzyl alcohol was added. [f] $10 \% \mathrm{v} / \mathrm{v}$ D-glucose was added. "Lemo" refers to E. coli Lemo21(DE3)_pAA

Table S4: Adipic acid production from catechol in $\mathrm{M} 9^{[\mathrm{a}]}$

\begin{tabular}{|l|l|l|l|l|l|l|}
\hline entry & E. coli BL21(DE3) & $\begin{array}{c}\text { OD }_{\text {600 }} \\
(\mathbf{a . u .})\end{array}$ & $\begin{array}{c}\text { Catechol } \\
(\mathbf{m M})\end{array}$ & $\begin{array}{c}\text { Muconic Acid } \\
(\mathbf{m M})\end{array}$ & $\begin{array}{c}\text { Adipic Acid } \\
(\mathbf{m M})\end{array}$ & $\begin{array}{c}\text { Yield } \\
(\mathbf{\%})\end{array}$ \\
\hline 1 & pAA & 122 & 0 & 0 & $3.5 \pm 0.06$ & $84 \pm 1.4$ \\
\hline 2 & pAA & 12 & 0 & $0.32 \pm 0.46$ & $2.6 \pm 0.77$ & $59 \pm 21$ \\
\hline 3 & pAA + pTf16 & 12 & 0 & 0 & $2.5 \pm 0.14$ & $77 \pm 1.3$ \\
\hline 4 & pAA + pGro7 & 12 & 0 & 0 & $4.0 \pm 0.04$ & $89 \pm 1.0$ \\
\hline 5 & pAA + pKJE7 & 12 & 0 & 0 & $4.3 \pm 0.04$ & $87 \pm 0.7$ \\
\hline 6 & pAAA $^{[b]}$ & 12 & 0 & $0.27 \pm 0.040$ & $2.8 \pm 0.10$ & $57 \pm 2.0$ \\
\hline
\end{tabular}

[a] reactions were incubated for $24 \mathrm{~h}$. [b] $10 \mathrm{mM}$ benzyl alcohol was added. 


\section{Time-course analysis}

Reactions were set-up as described previously. Each data point was generated from the analysis of separate culture tubes by HPLC.
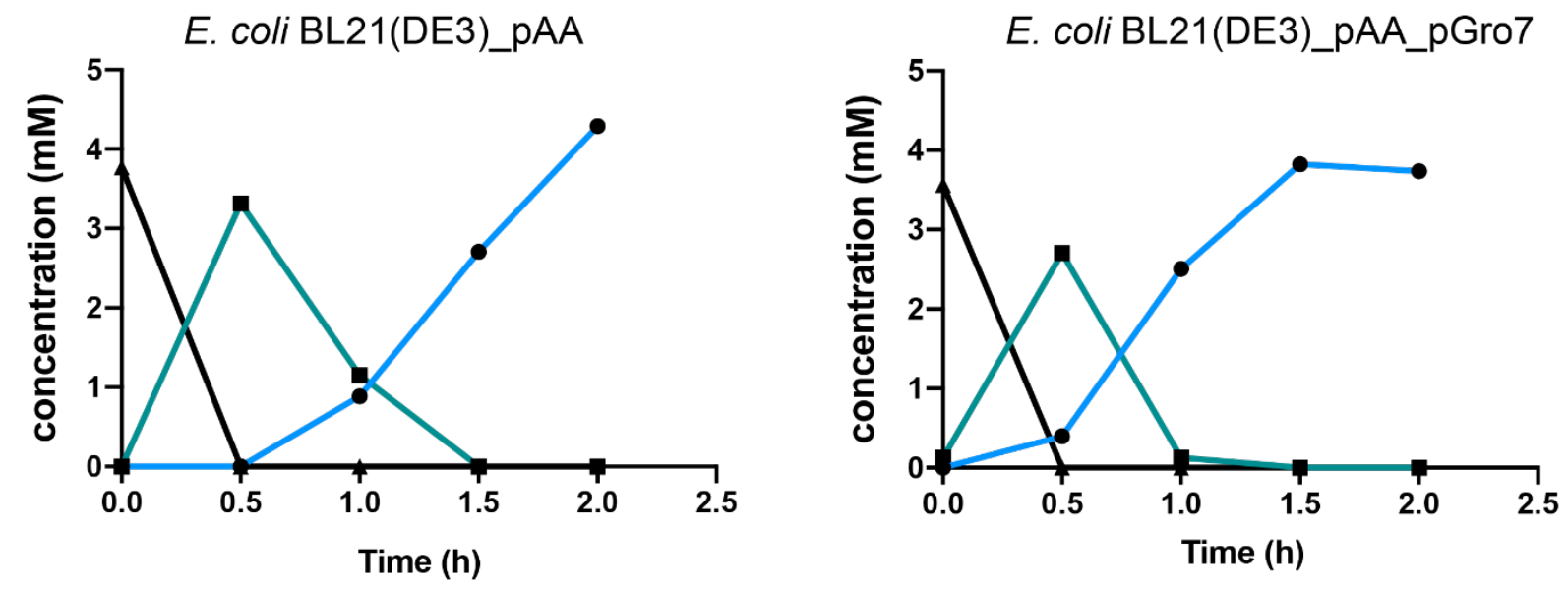

E. coli BL21(DE3)_pAA_pTf16

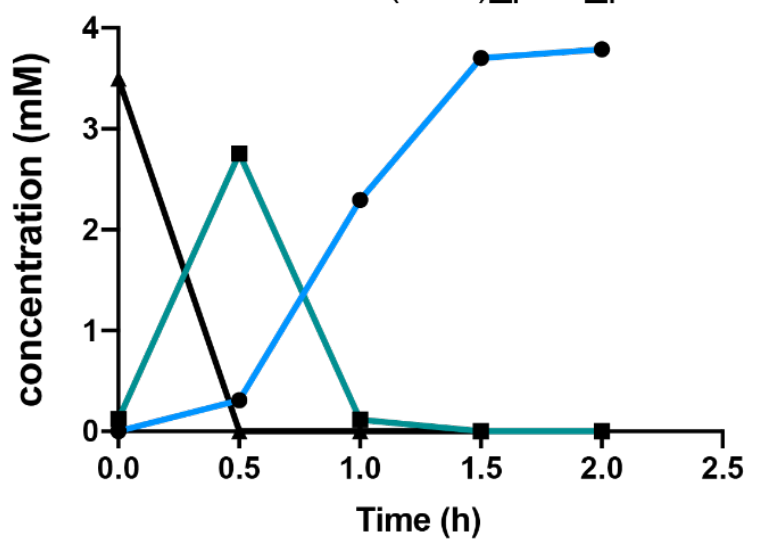

Adipic Acid

$\rightarrow$ Muconic Acid

\pm Catechol

Figure S5. Concentration of intermediates during the reaction

\section{Protein solubility}

Small-scale protein expression tests $(10 \mathrm{~mL}$ cultures) were carried out as described previously (see General Materials and Methods). Aliquots ( $1 \mathrm{~mL}$ ) were pelleted via centrifugation (1666 xg, $2 \mathrm{~min}$ ), the supernatant was discarded and cells were resuspended in $650 \mu \mathrm{L}$ cell lysis buffer ( $40 \mathrm{mM}$ sodium phosphate, pH 7.2, $100 \mathrm{mM} \mathrm{NaCl}$ ). Chicken egg white lysozyme (Sigma Aldrich) was added to a concentration of $1 \mathrm{mg} / \mathrm{mL}$ and samples were incubated at room temperature for $10 \mathrm{~min}$. Samples were then sonicated on ice ( 6 cycles of $10 \mathrm{~s}$ on/off at 5 amplitude microns). Aliquots of whole-cell extracts 
$(10 \mu \mathrm{L})$ were extracted before centrifuging the samples $\left(1666 \mathrm{xg}, 4{ }^{\circ} \mathrm{C}, 20 \mathrm{~min}\right)$. Aliquots of supernatant containing soluble protein extract $(10 \mu \mathrm{L})$ were collected and the remaining supernatant was discarded. Cell pellets were rinsed with cell lysis buffer $(3 \times 1 \mathrm{~mL})$ before adding further cell lysis buffer $(630 \mu \mathrm{L})$ and sonicating the samples on ice (10 s sonication at 5 amplitude microns). Aliquots of the resulting solution $(10 \mu \mathrm{L})$ were used to analyse insoluble protein fractions.

For SDS-PAGE, the protein samples $(10 \mu \mathrm{L})$ were added to $5 \mu \mathrm{L}$ of $4 \mathrm{x}$ SDS PAGE loading dye $(0.2 \mathrm{M}$ Tris-HCl, $\mathrm{pH} 6.8,8 \% \mathrm{v} / \mathrm{v}$ SDS, $20 \% \mathrm{v} / \mathrm{v}$ glycerol, $0.04 \% \mathrm{w} / \mathrm{v}$ bromophenol blue) and samples were heated at $95{ }^{\circ} \mathrm{C}$ for $2 \mathrm{~min}$. Samples were centrifuged at (1666 xg, $2 \mathrm{~min}$ ) and then $10 \mu \mathrm{L}$ of each sample was loaded onto a 12\% NuPAGE Bis/Tris gel. The gel was run under standard conditions as outlined previously. Gels were stained using SimplyBlue Stain (Invitrogen) before imaging using a Gel Doc $\mathrm{XR}+{ }^{\mathrm{TM}}$ (Biorad). Image $\mathrm{Lab}^{\mathrm{TM}}$ software (Biorad) was used to detect lanes and band intensities using the automatic detection function. Band intensities are reported as relative to the $50 \mathrm{kDa}$ ladder band in the same gel. 
E. coli BL21(DE3)_pAA

$-W \quad S$

75

50

35

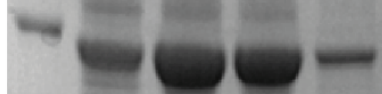

E. coli BL21(DE3)_pAA_pKJE7

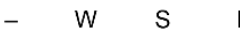

75

35

E. coli Lemo12(DE3)_pAA ${ }^{[c]}$

- W S I

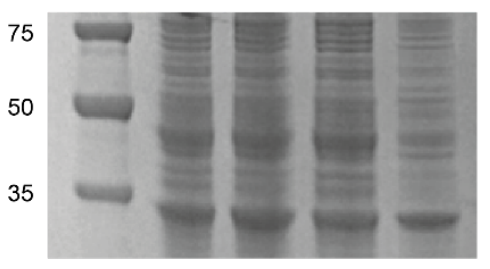

E. coli BL21(DE3) pAA pGro7

- W S

75

35

E. coli Lemo12(DE3)_pAA ${ }^{[a]}$
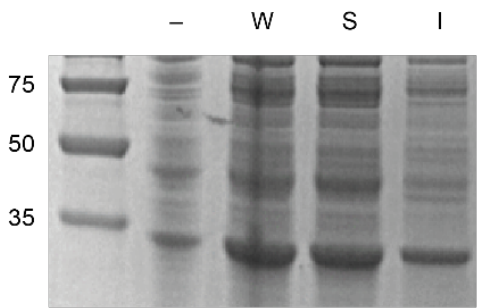

E. coli BL21(DE3) $\triangle i s c R \_p A A$

- W S I

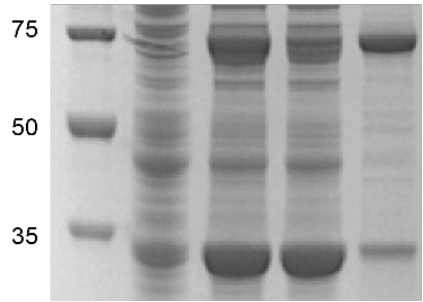

E. coli BL21(DE3)_pAA_pTf16

- W S I

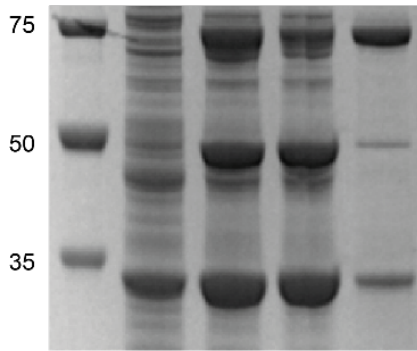

E. coli Lemo12(DE3)_pAA ${ }^{[\mathrm{b}]}$
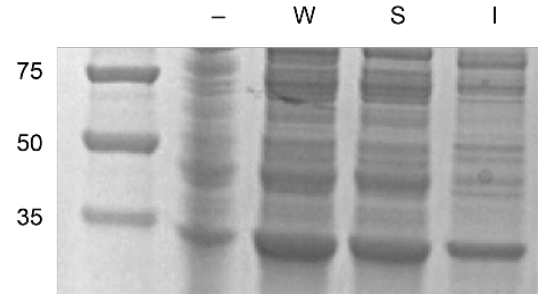

E. coli BL21(DE3)_pAA ${ }^{[\mathrm{d}]}$
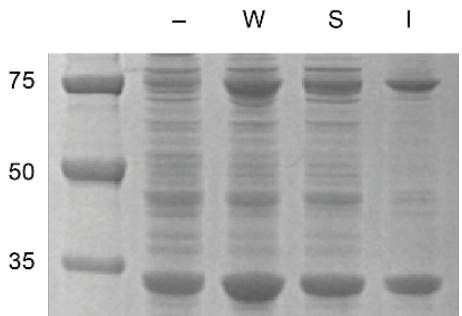

Figure S6. Analysis of protein solubility by SDS-PAGE. Whole cell, soluble and insoluble fractions are indicated by "W", "S" and "I", respectively. Uninduced controls are indicated by "-". BcER is $75 \mathrm{kDa}$ and and CatA is $35 \mathrm{kDa}$. [a] $10 \mu \mathrm{L}$ L-rhamnose was added. [b] $40 \mu \mathrm{M}$ L-rhamnose was added. [c] $100 \mu \mathrm{M}$ L-rhamnose was added. [d] $10 \mathrm{mM}$ benzyl alcohol was added. 
Table S5: BcER expression data

\begin{tabular}{|l|l|l|l|l|}
\hline Strain & WCE & \multicolumn{1}{|c|}{ Soluble } & \multicolumn{1}{|c|}{ Insoluble } & Soluble:Insoluble \\
\hline BL21(DE3)_pAA & $1.6 \pm 0.40$ & $0.75 \pm 0.05$ & $1.6 \pm 0.33$ & $0.49 \pm 0.12$ \\
\hline BL21(DE3)_pAA_pGro7 & $1.0 \pm 0.13$ & $0.57 \pm 0.02$ & $1.2 \pm 0.12$ & $0.49 \pm 0.06$ \\
\hline BL21(DE3)_pAA_pKJE7 & $1.7 \pm 0.13$ & $1.4 \pm 0.30$ & $0.75 \pm 0.24$ & $2.1 \pm 1.1$ \\
\hline BL21(DE3)_pAA_pTf16 & $1.8 \pm 0.09$ & $1.0 \pm 0.13$ & $1.2 \pm 0.23$ & $0.87 \pm 0.12$ \\
\hline Lemo21(DE3)_pAA ${ }^{[\mathrm{a}]}$ & $1.1 \pm 0.29$ & $0.63 \pm 0.16$ & $0.68 \pm 0.11$ & $0.91 \pm 0.10$ \\
\hline Lemo21(DE3)_pAA ${ }^{[\mathrm{b}] *}$ & $0.43 \pm 0.10$ & $0.25 \pm 0.11$ & $0.21 \pm 0.05$ & $1.2 \pm 0.33$ \\
\hline Lemo21(DE3)_pAA ${ }^{[\mathrm{c}] *}$ & $0.58 \pm 0.17$ & $0.35 \pm 0.03$ & $0.33 \pm 0.17$ & $1.3 \pm 0.58$ \\
\hline BL21(DE3)4iscR_pAA & $2.0 \pm 0.10$ & $0.65 \pm 0.06$ & $1.6 \pm 0.09$ & $0.40 \pm 0.04$ \\
\hline BL21(DE3)_pAA ${ }^{[\mathrm{d}]}$ & $0.87 \pm 0.12$ & $0.60 \pm 0.12$ & $0.56 \pm 0.03$ & $1.1 \pm 0.2$ \\
\hline
\end{tabular}

* indicates -IPTG control produces a $75 \mathrm{kDa}$ band with an intensity within the standard deviation of WCE samples. [a] $10 \mu \mathrm{L}$ L-rhamnose was added. [b] $40 \mu \mathrm{M}$ L-rhamnose was added. [c] 100 $\mu \mathrm{M}$ L-rhamnose was added. [d] $10 \mathrm{mM}$ benzyl alcohol was added.

Table S6: CatA expression data

\begin{tabular}{|l|c|c|c|l|}
\hline Strain & WCE & Soluble & Insoluble & Soluble:Insoluble \\
\hline BL21(DE3)_pAA & $2.2 \pm 0.23$ & $2.0 \pm 0.24$ & $0.68 \pm 0.09$ & $2.9 \pm 0.19$ \\
\hline BL21(DE3)_pAA_pGro7 & $1.8 \pm 0.04$ & $1.8 \pm 0.09$ & $0.47 \pm 0.03$ & $3.8 \pm 0.14$ \\
\hline BL21(DE3)_pAA_pKJE7* & $1.1 \pm 0.03$ & $1.0 \pm 0.09$ & $0.47 \pm 0.03$ & $2.2 \pm 0.04$ \\
\hline BL21(DE3)_pAA_pTf6 & $1.7 \pm 0.12$ & $1.6 \pm 0.13$ & $0.40 \pm 0.08$ & $4.0 \pm 0.58$ \\
\hline Lemo21(DE3)_pAA ${ }^{[\mathrm{a}]}$ & $1.2 \pm 0.06$ & $1.2 \pm 0.24$ & $0.67 \pm 0.04$ & $1.8 \pm 0.25$ \\
\hline Lemo21(DE3)_pAA ${ }^{[\mathrm{b}]}$ & $0.98 \pm 0.31$ & $1.1 \pm 0.21$ & $0.62 \pm 0.14$ & $1.9 \pm 0.09$ \\
\hline Lemo21(DE3)_pAA ${ }^{[\mathrm{c}]}$ & $0.57 \pm 0.11$ & $0.67 \pm 0.13$ & $0.64 \pm 0.07$ & $1.1 \pm 0.16$ \\
\hline BL21(DE3)4iscR_pAA & $2.1 \pm 0.12$ & $1.9 \pm 0.13$ & $0.61 \pm 0.14$ & $3.2 \pm 0.89$ \\
\hline BL21(DE3)_pAA ${ }^{[\mathrm{d}]}$ & $1.1 \pm 0.12$ & $0.76 \pm 0.10$ & $0.65 \pm 0.11$ & $1.2 \pm 0.21$ \\
\hline
\end{tabular}

* indicates -IPTG control produces a $35 \mathrm{kDa}$ band with an intensity within the standard deviation of WCE samples. [a] $10 \mu \mathrm{L}$ L-rhamnose was added. [b] $40 \mu \mathrm{M}$ L-rhamnose was added. [c] 100 $\mu \mathrm{M}$ L-rhamnose was added. [d] $10 \mathrm{mM}$ benzyl alcohol was added. 


\section{Production of adipic acid from guaiacol}

To produce adipic acid from guaiacol, E. coli BL21(DE3)_pAA' was cultured as described previously, except LB or M9-glucose media was used instead of TB and cells were induced using IPTG (0.4 mM) at $\mathrm{OD}_{600}=0.4-0.5$. At this point, 5 -aminolevulinic acid $(0.76 \mathrm{mM})$ and ammonium iron(III) citrate $(0.76$ $\mathrm{mM}$ ) were also added. ${ }^{4}$ After $18 \mathrm{~h}$ of protein expression, whole-cell reactions were prepared as outlined previously. Reactions were carried out in M9 reaction buffer (M9 media, 3\% w/v glucose, $5 \mathrm{mM}$ guaiacol) and incubated at $37{ }^{\circ} \mathrm{C}(220 \mathrm{rpm})$ for $24 \mathrm{~h}$ prior to extraction and analysis by HPLC.

Table S7: Adipic acid production from guaiacol ${ }^{[a]}$

\begin{tabular}{|c|c|c|c|c|c|c|}
\hline entry & $\begin{array}{c}\text { E. coli } \\
\text { BL21(DE3) }\end{array}$ & $\begin{array}{c}\text { Protein } \\
\text { Expression } \\
\text { Media }\end{array}$ & $\begin{array}{l}\text { OD }_{600} \\
\text { (a.u.) }\end{array}$ & $\begin{array}{c}\text { Muconic } \\
\text { Acid (mM) }\end{array}$ & $\begin{array}{c}\text { Adipic } \\
\text { Acid } \\
(\mathbf{m M})\end{array}$ & $\begin{array}{c}\text { Yield } \\
(\%)\end{array}$ \\
\hline 1 & $\mathrm{pAA}^{\prime}$ & TB & 122 & 0 & $0.61 \pm 0.02$ & $14 \pm 0.47$ \\
\hline 2 & $\mathrm{pAA}^{\prime}$ & LB & 61 & 0 & 0 & 0 \\
\hline 3 & $\mathrm{pAA}^{\prime}$ & LB & 30 & 0 & $2.6 \pm 0.28$ & $53 \pm 5.6$ \\
\hline 4 & $\mathrm{pAA}^{\prime}$ & LB & 20 & 0 & $2.8 \pm 0.14$ & $56 \pm 2.8$ \\
\hline 5 & $\mathrm{pAA}^{\prime}$ & LB & 12 & 0 & $2.3 \pm 0.50$ & $47 \pm 10$ \\
\hline 6 & $\mathrm{pAA}^{\prime}$ & LB & 6 & $1.9 \pm 0.15$ & $0.74 \pm 0.07$ & $15 \pm 1.4$ \\
\hline 7 & $\mathrm{pAA}^{\prime}$ & M9 & 61 & 0 & 0 & 0 \\
\hline 8 & $\mathrm{pAA}^{\prime}$ & M9 & 30 & 0 & $2.0 \pm 0.05$ & $40 \pm 1$ \\
\hline 9 & $\mathrm{pAA}^{\prime}$ & M9 & 20 & 0 & $3.0 \pm 0.67$ & $61 \pm 14$ \\
\hline 10 & $\mathrm{pAA}^{\prime}$ & M9 & 12 & $0.47 \pm 0.23$ & $1.3 \pm 0.59$ & $32 \pm 14$ \\
\hline 11 & $\mathrm{pAA}^{\prime}$ & M9 & 6 & $3.3 \pm 0.06$ & $0.16 \pm 0.15$ & $3.2 \pm 3.1$ \\
\hline 12 & pAA'Rr & LB & 61 & 0 & $0.26 \pm 0.05$ & $5.6 \pm 1.1$ \\
\hline
\end{tabular}

[a] reactions were incubated for $24 \mathrm{~h}$.

Table S8 Adipic acid production from catechol using E. coli BL21(DE3)_pAA'

\begin{tabular}{|l|l|l|l|l|l|c|}
\hline entry & $\begin{array}{c}\text { E. coli } \\
\text { BL21(DE3) }\end{array}$ & $\begin{array}{c}\text { Formaldehyde } \\
\text { added? } \\
\mathbf{( 5 ~} \mathbf{~ m M})\end{array}$ & $\begin{array}{c}\text { OD }_{\text {600 }} \\
\mathbf{( a . u . )}\end{array}$ & $\begin{array}{c}\text { Muconic } \\
\text { Acid (mM) }\end{array}$ & $\begin{array}{c}\text { Adipic } \\
\text { Acid } \\
(\mathbf{m M})\end{array}$ & $\begin{array}{c}\text { Yield } \\
\mathbf{( \% )}\end{array}$ \\
\hline 1 & pAA $^{\prime}$ & yes & 122 & 0 & $4.3 \pm 0.04$ & $98 \pm 0.86$ \\
\hline 2 & pAA $^{\prime}$ & no & 122 & 0 & $4.1 \pm 0.03$ & $92 \pm 0.69$ \\
\hline
\end{tabular}


Table S9 Relative quantity of unreacted guaiacol

\begin{tabular}{|l|l|l|l|l|}
\hline entry & $\begin{array}{c}\text { E. coli } \\
\text { BL21(DE3) }\end{array}$ & $\begin{array}{c}\text { Protein } \\
\text { Expression } \\
\text { Media }\end{array}$ & $\begin{array}{c}\text { OD }_{\text {600 }} \\
\text { (a.u.) }\end{array}$ & $\begin{array}{c}\text { Relative } \\
\text { guaiacol } \\
\text { concentration } \\
\text { (\%) }\end{array}$ \\
\hline 1 & pAA' & LB & 61 & $95 \pm 5.4$ \\
\hline 2 & pAA' & LB & 30 & $45 \pm 3.8$ \\
\hline 3 & pAA' & LB & 20 & $36 \pm 3.9$ \\
\hline 4 & pAA' & LB & 12 & $19 \pm 9.1$ \\
\hline 5 & pAA' & LB & 6 & $13 \pm 4.1$ \\
\hline 6 & pAA' & M9 & 61 & $88 \pm 4.5$ \\
\hline 7 & pAA' & M9 & 30 & $63 \pm 5.4$ \\
\hline 8 & pAA' & M9 & 20 & $28 \pm 17$ \\
\hline 9 & pAA' & M9 & 12 & $7.9 \pm 2.5$ \\
\hline 10 & pAA' & M9 & 6 & $14 \pm 5$ \\
\hline
\end{tabular}

\section{Formaldehyde quantification}

Quantification of formaldehyde was adapted from Yue et al., 2017. ${ }^{[5]}$ A standard curve was generated by adding $25 \mu \mathrm{L}$ of aqueous formaldehyde solution $(0.1-10 \mathrm{mM})$ to $\mathrm{M} 9$ media $(975 \mu \mathrm{L})$ containing glucose (3\% w/v) and 4-amino-3-penten-2-one (Fluoral-P, $2 \mathrm{mM})$. Samples were mixed thoroughly and incubated at room temperature for $1 \mathrm{~h}$ before the absorbance at $420 \mathrm{~nm}$ was measured. This gave the linear relationship $\mathrm{A}_{420}=0.0964 \mathrm{c}_{\text {formaldehyde }}-0.038$ (Figure $\mathrm{S} 7$ ). To measure formaldehyde in biological samples, $200 \mu \mathrm{L}$ reaction aliquots were pelleted $(1666 \mathrm{xg}, 2 \mathrm{~min})$ and then $25 \mu \mathrm{L}$ of supernatant was added to M9 media $(975 \mu \mathrm{L})$ containing glucose $(3 \% \mathrm{w} / \mathrm{v})$ and 4-amino-3-penten-2-one $(2 \mathrm{mM})$. Samples were mixed thoroughly and incubated at room temperature for $1 \mathrm{~h}$ before the absorbance at $420 \mathrm{~nm}$ was measured. Dead cell solutions were prepared by heating cultures to $90{ }^{\circ} \mathrm{C}$ for $1 \mathrm{~h}$ before the addition of formaldehyde. 


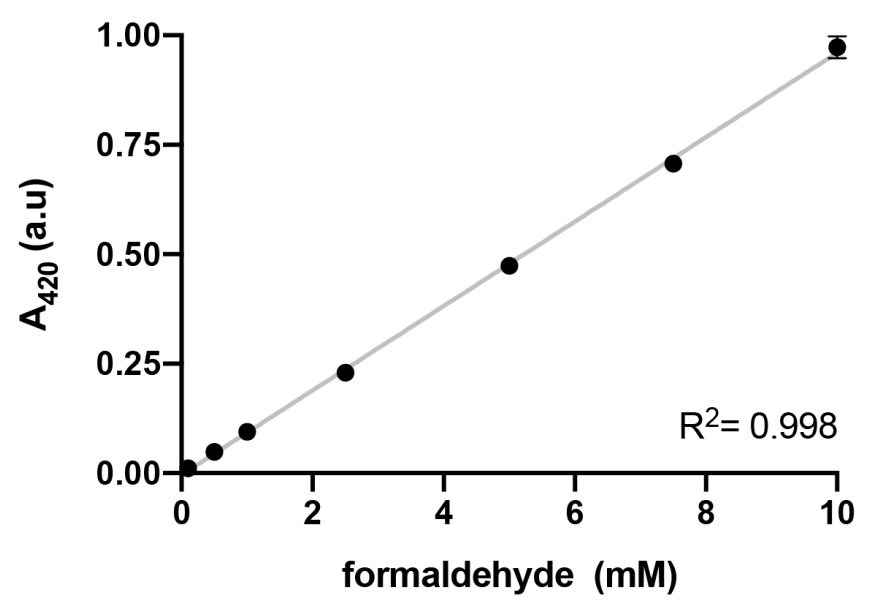

Figure S7. Calibration curve for formaldehyde
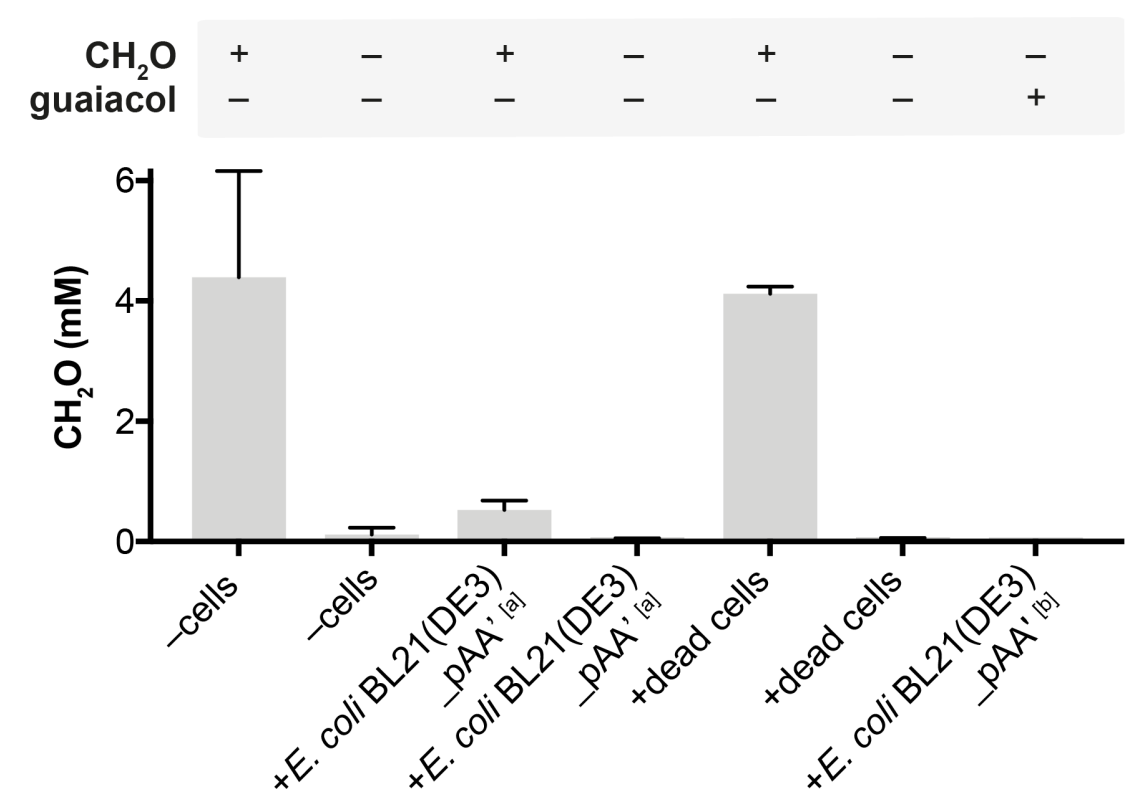

Figure S8. Analysing formaldehyde concentrations using a Fluoral-P colorimetric assay. [a] noninduced cells. [b] cells were induced using $0.4 \mathrm{mM}$ IPTG.

\section{Cell viability}

Reactions were set-up as described previously using Na-Pi buffer and M9 media and at $\mathrm{OD}_{600}=122$ and $\mathrm{OD}_{600}=12$. Following incubation of reactions for $24 \mathrm{~h}\left(37{ }^{\circ} \mathrm{C}, 220 \mathrm{rpm}\right), 10 \mu \mathrm{L}$ of each reaction was 
inoculated into LB media $(10 \mathrm{~mL})$ and samples were incubated for a further $24 \mathrm{~h}\left(37^{\circ} \mathrm{C}, 220 \mathrm{rpm}\right)$. After this time the $\mathrm{OD}_{600}$ of each sample was recorded.
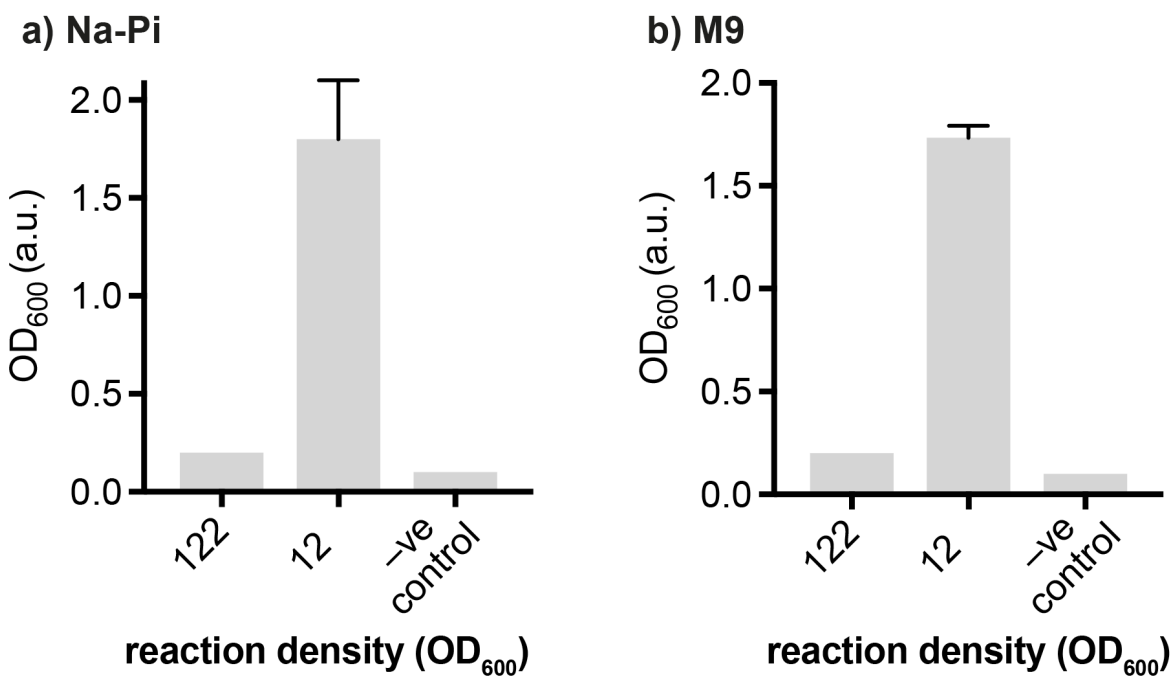

Figure S9. $\mathrm{OD}_{600}$ of cell cultures inoculated from biocatalytic reactions. All values are average of 3 biological replicates $+/$ - one standard deviation.

\section{Synthesis}

\section{Synthesis of 2-hexenedioic acid}

\section{(E)-dimethyl hex-2-enedioate}<smiles>COC(=O)/C=C/CCC(=O)OC</smiles>

Procedure adapted from Dannecker et al., 2018. ${ }^{[6]}$

Methyl 4-pentenoate $(0.55 \mathrm{ml}, 4.4 \mathrm{mmol})$, methyl acrylate $(4.13 \mathrm{ml}, 44 \mathrm{mmol})$ and $p$-benzoquinone $(0.049 \mathrm{~g}, 0.45 \mathrm{mmol})$ were degassed for $10 \mathrm{~min}$. Hoveyda-Grubbs catalyst $2^{\text {nd }}$ generation $(25 \mathrm{mg}, 0.04$ mmol) was added and the mixture was heated to $50{ }^{\circ} \mathrm{C}$ for $16 \mathrm{~h}$. The excess methyl acrylate was removed under reduced pressure. The product was purified by column chromatography (PET ether 5/1 diethyl ether, $\left.\mathrm{R}_{\mathrm{f}}=0.2\right)$ to yield (E)-dimethyl hex-2-enedioate, a clear oil $(0.512 \mathrm{~g}, 3.0 \mathrm{mmol}, 68 \%)$

${ }^{1} \mathbf{H}$ NMR $\left(500 \mathrm{MHz}, \mathrm{CDCl}_{3}\right) 6.96(\mathrm{dt}, J=15.7,6.4 \mathrm{~Hz}, 1 \mathrm{H}), 5.87(\mathrm{dt}, J=15.7,1.6 \mathrm{~Hz}, 1 \mathrm{H}), 3.74(\mathrm{~s}$, $3 \mathrm{H}), 3.70(\mathrm{~s}, 3 \mathrm{H}), 2.59-2.51(\mathrm{~m}, 2 \mathrm{H}), 2.51-2.46(\mathrm{~m}, 2 \mathrm{H})$ 
${ }^{13}$ C NMR (126 MHz, $\left.\mathrm{CDCl}_{3}\right)$ 172.67, 166.78, 146.85, 121.89, 51.78, 51.49, 32.25, 27.21

NMR data were in accordance with the published literature. ${ }^{7}$

\section{2-hexenedioic acid}<smiles>O=C(O)/C=C/CCC(=O)O</smiles>

Procedure adapted from Sølvhøj et al., 2016..$^{[7]}$

Lithium hydroxide $(0.46 \mathrm{~g}, 20 \mathrm{mmol})$ was added to a stirred solution of (E)-dimethyl hex-2-enedioate in a mixture of THF:methanol:water $(3: 3: 3,18 \mathrm{ml})$. After $24 \mathrm{~h}$ the mixture was extracted with ethyl acetate $(3 \times 20 \mathrm{ml})$. The aqueous phase was adjusted to $\mathrm{pH} 3$ with hydrochloric acid $(2 \mathrm{M}, 10 \mathrm{ml})$ and then extracted with ethyl acetate $(3 \times 20 \mathrm{ml})$. The combined organic layers were washed with water $(20$ $\mathrm{ml})$ and brine $(20 \mathrm{ml})$, dried over magnesium sulfate, filtered and concentrated in vacuo. The crude product was purified by flash column chromatography (8:2:0.05 ethyl acetate/methanol/acetic acid) to give $\alpha$-hydrinuconic acid as a white crystalline solid. (0.180 g, $1.25 \mathrm{mmol}, 42 \%)$

${ }^{1} \mathbf{H}$ NMR $\left(500 \mathrm{MHz}, \mathrm{CDCl}_{3}\right) 7.03-6.93(\mathrm{~m}, 1 \mathrm{H}), 5.86(\mathrm{dt}, J=15.7,1.5 \mathrm{~Hz}, 1 \mathrm{H}), 2.58-2.43(\mathrm{~m}, 4 \mathrm{H})$

${ }^{13}$ C NMR (126 MHz, $\left.\mathrm{CDCl}_{3}\right)$ 174.75, 168.51, 147.61, 121.87, 31.84, 26.90

NMR data were in accordance with the published literature ${ }^{[8]}$. 


\section{(E)-dimethyl hex-2-enedioate}

${ }^{1} \mathrm{H}$ NMR

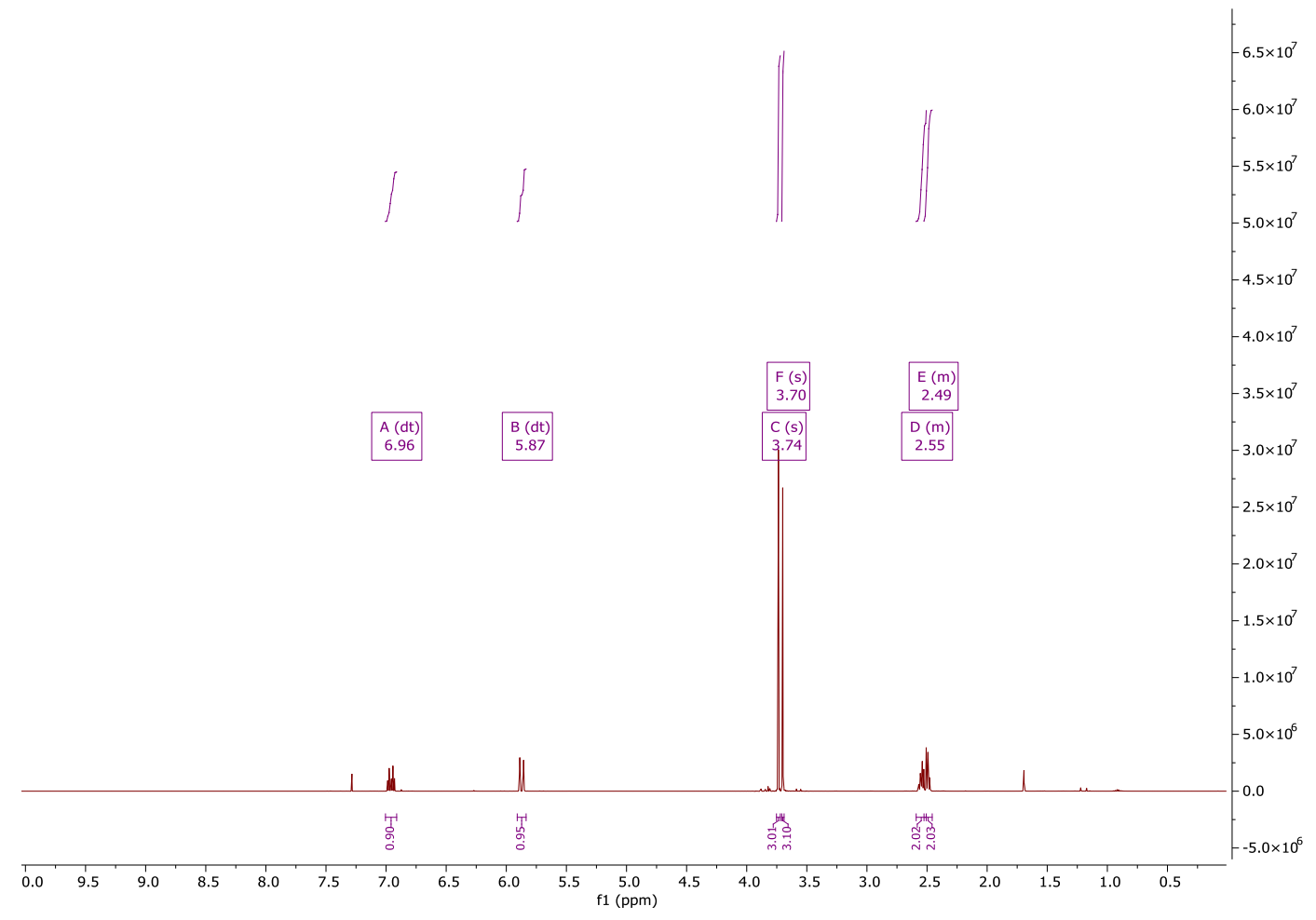

${ }^{13} \mathrm{C}$ NMR

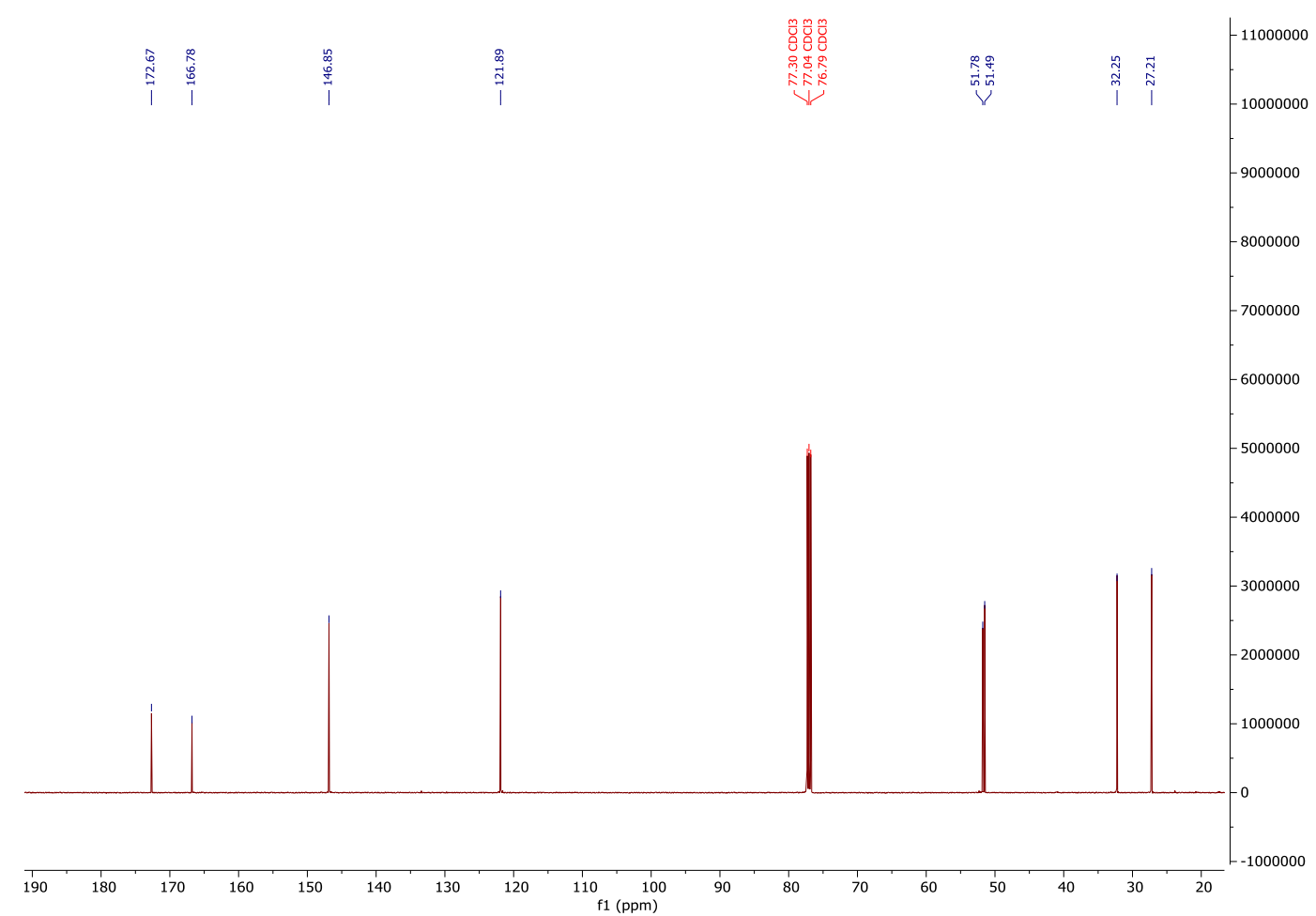




\section{2-hexenedioic acid}

${ }^{1} \mathrm{H}$ NMR

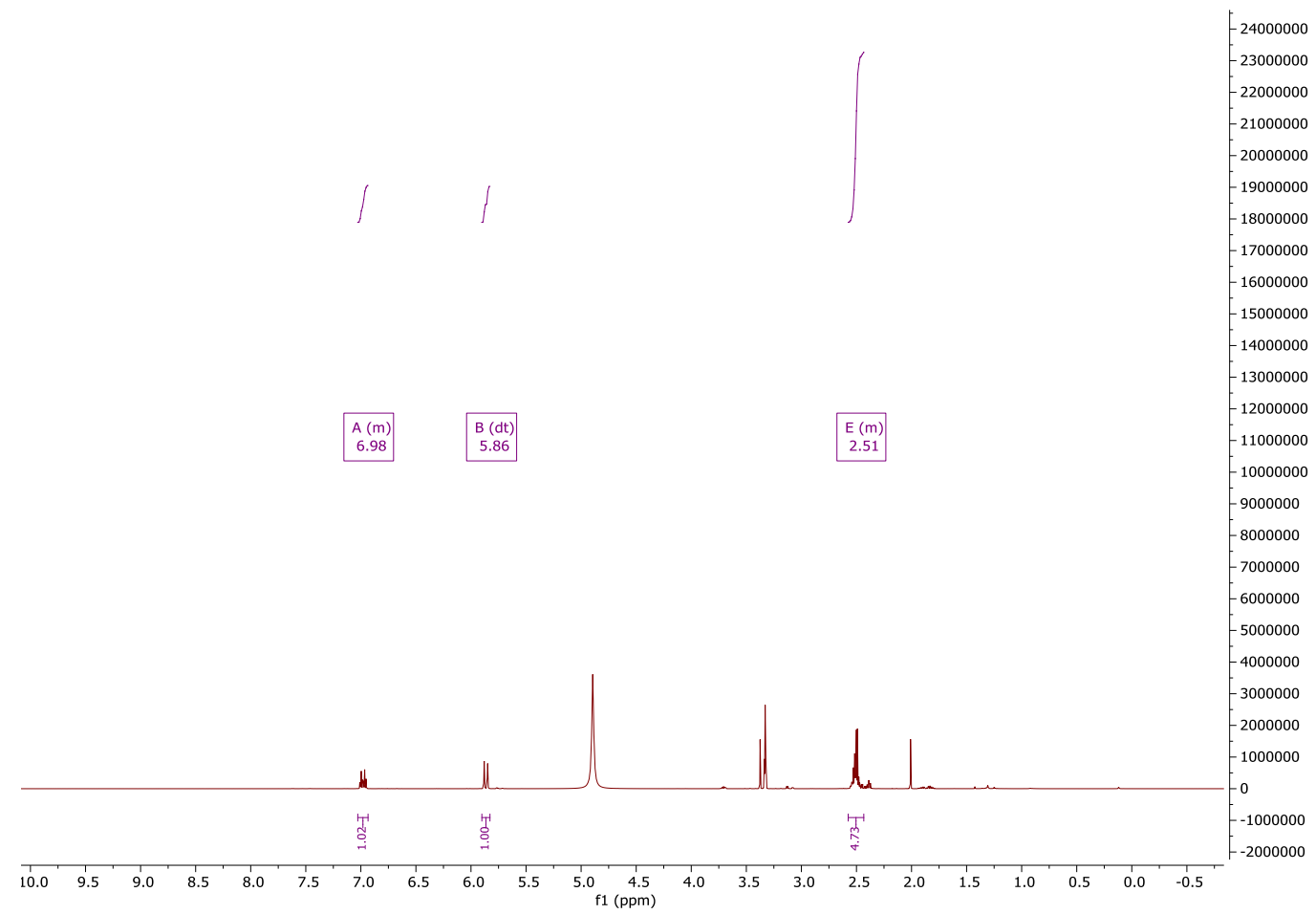

\section{${ }^{13} \mathrm{C}$ NMR}

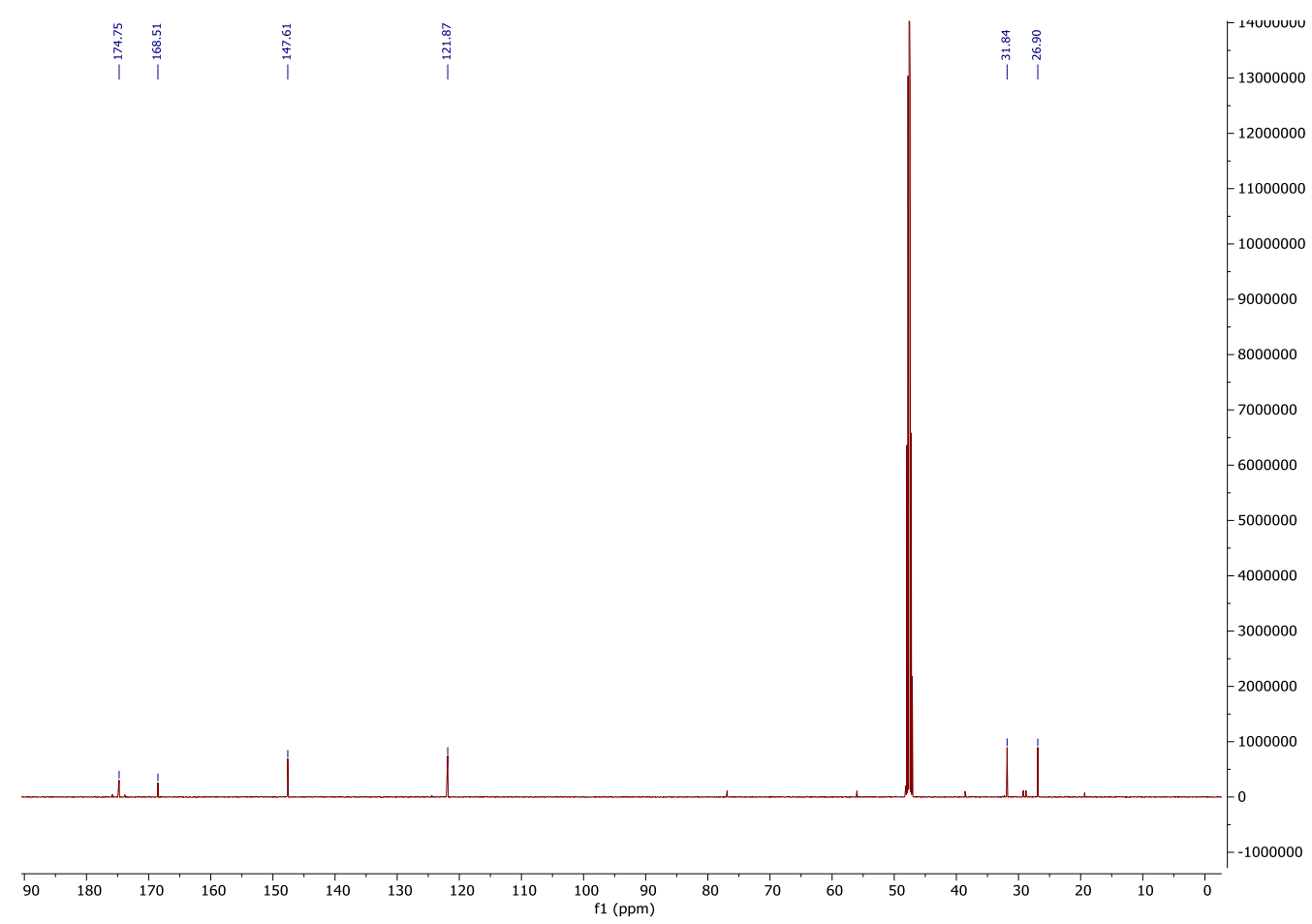




\section{S6 References}

[1] Cohen, S. N.; Chang, A. C. Y.; Hsu, L. Nonchromosomal Antibiotic Resistance in Bacteria: Genetic Transformation of Escherichia coli by R-Factor DNA* PNAS. 1972, 69(8), 2110-2114. DOI: 10.1073/pnas.69.8.2110

[2] Sawitzke, J.; Thomason, L.; Costantino, N.; Bubunenko, M.; Datta, S.; Court, D. Recombineering: in vivo genetic engineering in E. coli, S. enterica, and beyond. Methods in Enzymology, 2015, 533, 81 101. DOI: $10.1016 / \mathrm{S} 0076-6879(06) 21015-2$

[3] Scheich, C.; Kümmel, D.; Soumailakakis, D.; Heinemann, U.; Büssow, K. Vectors for co-expression of an unrestricted number of proteins Nucleic Acids Res. 2007, 35, e43. DOI: 10.1093/nar/gkm067

[4] Mallinson, S. J. B.; Machovina, M. M.; Silveira, R. L.; Gacria-Borràs, M.; Gallup, N.; Johnson, C. W.; Allen, M. D.; Skaf, M. S.; Crowley, M. F.; Neidle, E. L.; Houk, K. N.; Beckham, G. T.; Dubois, J. L.; McGeehan, J. E. Nat. Commun. 2018, 9, 2487.

[5] Yue, X.; Zhang, Y.; Xing, W.; Chen, Y.; Mu, C.; Miao, Z.; Ge, P.; Li, T.; He, R.; Tong, Z. A Sensitive and Rapid Method for Detecting Formaldehyde in Brain Tissues. Analytical Cellular Pathology 2017, 2017, 1-8. DOI: 10.1155/2017/9043134

[6] Dannecker, P.; Biermann, U.; von Czapiewski, M.; Metzger, J. O.; Meier, M. A. R. Renewable Polyethers via GaBr3-Catalyzed Reduction of Polyesters Angew. Chem. Int. Ed. 2018, 57, 8775-8779. DOI: 10.1002/anie.201804368

[7] Sølvhøj, A.;Taarning, E.; Madsen, R. Methyl vinyl glycolate as a diverse platform molecule Green Chem., 2016, 20, 5448. DOI: 10.1039/C6GC01556E

[8] Sirasani, G.; Tong, L.; Balskus, E. P. A Biocompatible Alkene Hydrogenation Merges Organic Synthesis with Microbial Metabolism Angew. Chem. Int. Ed. 2014, 53, 7785-7788. DOI: 10.1002/anie. 201403148 